\title{
Bandwidth-Enhanced of Siw Cavity-Backed Slot Antenna By Perturbing Te210 Cavity Mode
}

\author{
Bollavathi Lokeshwar', Dorai Venkatasekhar ${ }^{2}$ and Alapati Sudhakar ${ }^{3}$ \\ ${ }^{1}$ Research Scholar, Department of ECE, Annamalai University, Annamalainagar 608002, India, \\ ${ }^{2}$ Professor, Department of IT, Annamalai University, Annamalainagar 608002, India \\ ${ }^{3}$ Professor, Department of ECE, R.V.R \& J.C College of Engineering, Guntur 522019, India
}

\section{ABSTRACT}

In this article, a technique is introduced for bandwidth enhancement of substrate integrated waveguide (SIW) based cavitybacked slotted antenna, inspired by the perturbing the cavity modes. To enhance the bandwidth, the proposed antenna uses a single cavity mode (TE210) instead of multiple cavity modes, which is the most diverse approach as compared to the other SIW cavity antennas. Due to the strong loading effect of the rectangle slot, the proposed antenna perturbs the TE210 cavity mode. As a result, two modes namely odd TE210 and even TE210 are successfully generated. Then a wideband response can be achieved by merging these modes in close proximity. The simulated findings show that the proposed design exhibits a fractional bandwidth of $12.8 \%$ and a peak gain of more than $6 \mathrm{dBi}$. The cross-polarization radiation level of maximum $-31 \mathrm{~dB}$ and $-35 \mathrm{~dB}$ and identical polarization planes are obtained at $9.75 \mathrm{GHz}$ and 10.65 $\mathrm{GHz}$, respectively. Those amicable properties, e.g., light weight, ease of fabrication, cost effective, broadband response, unidirectional pattern, and high gain, make the design suitable for X-band applications.

\section{KEY WORDS: SUBSTRATE INTEGRATED WAVEGUIDE, HYBRID MODE, WIDEBAND, IMPEDANCE BANDWIDTH.}

\section{INTRODUCTION}

Substrate integrated technology (SIW) is the latest available technology that realizes the future wireless systems in planar form. The amicable benefits of this technology are the high-density integration with planar circuits and the low power losses [Kumar A et. al]. Several papers have been reported on SIW cavity-backed antennas. One of the major drawbacks of these antennas is the narrow bandwidth due to thin substrate. Low-profile planar slot antenna by using SIW technique is reported in [Luo GQ et. al], which generates the radiation by TE120

\section{ARTICLE INFORMATION}

*Corresponding Author: lokesh5701@gmail.com

Received 18th Oct 2020 Accepted after revision 30th Dec 2020

Print ISSN: 0974-6455 Online ISSN: 2321-4007 CODEN: BBRCBA

Thomson Reuters ISI Web of Science Clarivate Analytics USA and Crossref Indexed Journal

\section{Clarivate
Analytics}

NAAS Journal Score 2020 (4.31)

A Society of Science and Nature Publication,

Bhopal India 2020. All rights reserved.

Online Contents Available at: http//www.bbrc.in/

Doi: $h t t p: / / d x$.doi.org/10.21786/bbrc/13.14/74 mode of the cavity at $10 \mathrm{GHz}$. Nevertheless, due to lowheight, the quality factor (Q) of the cavity is increased. As a result, the bandwidth is achieved nearly $1.7 \%$ with a gain of $5.3 \mathrm{dBi}$. In [Luo GQ et. al], fractional bandwidth of $6.3 \%$ is obtained by coupling the two hybrid modes (combinations of the TE110 and TE120 modes) of the cavity in close proximity. In [Mukherjee S et. al], TE120 mode is excited by using offset feeding technique. As a result, impedance bandwidth of $4.2 \%$ is achieved.

In [Mukherjee $\mathrm{S}$ et. al], the modified bow-tie slot perturbs the TE110 and TE120 modes to improve the bandwidth upto 9.4\%. In [Baghernia $\mathrm{E}$ et. al], corner perturbation in the square cavity separates the TE120 and TE210 cavity modes, which in turn enhances the bandwidth (1.65\%). In [Varnoosfadetrani MV et. al], matching slot excite the TE210 mode in the SIW cavity to attain the fractional bandwidth upto 8\%. In [Dashti H et. al], TM010 mode of the patch is stimulated through proximity coupling by half-mode SIW to improve the impedance bandwidth. In [Kumar A et. al], multi-resonant slots perturb the current distributions of both TE110 and TE120 modes. As a result,

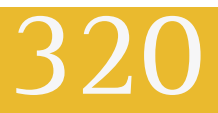


the antenna achieves an impedance bandwidth upto 11\%. Development of wideband is presented in [Heydarzadeh F et. al], where TE120 and TE210 degenerate modes of the SIW cavity are greatly coupled by cutting the corners of the conventional SIW cavity with circular shape. This design achieves $5.7 \%$ fractional impedance bandwidth. Bandwidth enhancement using bilateral slots have been reported in [Niu BJ et. al], in which three hybrid modes have been merged within the operating band. In [Feng $\mathrm{C}$ et. al], to enhance the impedance bandwidth up to $8.9 \%$, the ellipse slot is employed in the circular SIW cavity. Several attempts have been discussed for bandwidth enhancement, by introducing two shorting vias nearby the inclined slot, by using stacked cavities, by using bilateral slots, by using metallic vias.

In this paper, low-profile slot antenna using SIW technology is proposed for obtaining wideband response. The proposed antenna utilizes a single cavity mode instead of multiple modes, which is the most distinct approach as compared to other approaches reported in the references. Due to the strong loading effect of the slot, the proposed structure disturbs the current distributions of the TE210 cavity mode. As a result, two modes namely odd TE210 and even TE210 are successfully developed. Then a wideband response of $12.8 \%$ bandwidth can be obtained by merging these modes in close proximity. The simulated findings are compared with the previously reported works for more extensive study.

Antenna Design: The configuration and parameters of the proposed antenna is illustrated in Fig. 1. It consists of a SIW cavity, radiating slot and feeding circuit. The SIW cavity is fully created on a single PCB of height h, where the lateral walls of the cavity are realized by implanting metallic posts along the edges of the substrate. Rogers RT/ duroid 5880 substrate $\left(\varepsilon_{\mathrm{r}}=2.2\right)$ is elected as the dielectric due to its exemplary features like low losses, less relative permittivity etc. The post diameter (d) and pitch (s) must pursue the prescribed criteria $d / s \geq 0.5$ and $d / \lambda 0 \leq 0$. 1 to minimize the energy leakage from the gap between successive metallic posts [Lokeshwar B]. The dimensions of the SIW cavity can be approximately determined from the equation (1). The radiating slot with size of $\mathrm{l}_{\mathrm{s}} \mathrm{X} \mathrm{w}_{\mathrm{s}}$ is printed on the ground plane. To facilitate the planar integration, a section of $50 \Omega$ micro-strip line is appended at the end of $50 \Omega$ grounded co-planar waveguide (GCPW), forming a feeding circuit to excite the proposed antenna.

$$
f_{r}\left(T E_{210}\right)=\frac{1}{2 \sqrt{\mu_{0} \varepsilon_{0} \varepsilon_{r}}} \sqrt{\left(\frac{m}{L_{e f f}}\right)^{2}+\left(\frac{n}{W_{e f f}}\right)^{2}+\left(\frac{p}{h}\right)^{2}}
$$

where, $\mathrm{m}, \mathrm{n}, \mathrm{p}$ are positive integers, $\varepsilon_{\mathrm{r}}-$ dielectric constant, equivalent length and width of the cavity

$$
\left(L_{e f f} \text { or } W_{e f f}\right)=L_{c a v} \text { or } W_{c a v}-\frac{d^{2}}{0.95 * s}
$$

respectively, $\mathrm{d}$ - diameter of the post, and p - spacing between the adjacent vias (pitch).
Figure 1: Configuration of the antenna a 3D View, b Schematic layout

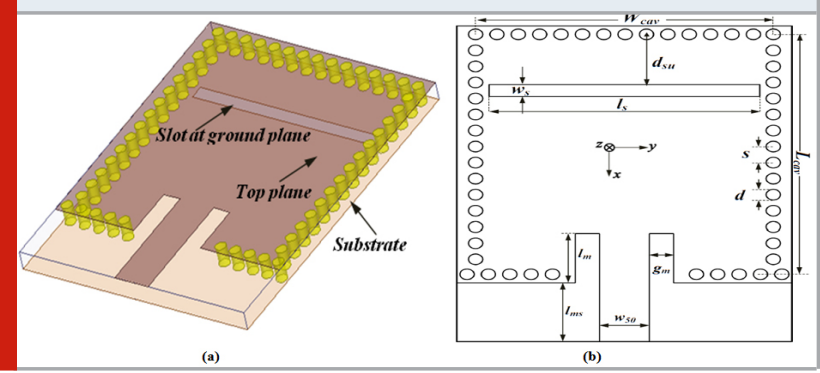

Table 1. Dimensional parameters of the proposed design

\begin{tabular}{|c|c|c|c|c|c|c|}
\hline Parameter & $\mathrm{W}_{\text {cav }}$ & $\mathrm{L}_{\text {cav }}$ & $\mathrm{w}_{50}$ & $\mathrm{l}_{\mathrm{ms}}$ & $\mathrm{l}_{\mathrm{m}}$ & $\mathrm{g}_{\mathrm{m}}$ \\
\hline Value(mm) & 20.9 & 22.4 & 3.3 & 5.5 & 4.6 & 1.25 \\
\hline Parameter & $\mathrm{ls}$ & $\mathrm{ws}$ & $\mathrm{dsu}$ & $\mathrm{s}$ & $\mathrm{d}$ & $\mathrm{h}$ \\
\hline Value(mm) & 19 & 1.4 & 4.55 & 1.5 & 1 & 1.6 \\
\hline
\end{tabular}

3. Working Principle: In order to figure out the behavior of the rectangle slot on bandwidth enhancement, the simulation of the SIW cavity is described by using ANSYS HFSS at first. One of the approach to improve the operating bandwidth of cavity-backed antennas is to increase the height of the substrate material. That's why, a standard thickness $\mathrm{h}=1.6 \mathrm{~mm}$ is selected as substrate thickness. The dimensions of the SIW cavity are optimized and listed in the Table 1. Fig. 2 represents the input resistance plot $(\operatorname{Re}(\mathrm{Z} 11))$ of the proposed design. When the SIW cavity alone is excited by micro-strip line feed, the dominant mode $\left(\mathrm{TE}_{110}\right)$ at $6.85 \mathrm{GHz}$ and $\mathrm{TE}_{210}$ mode at $10.25 \mathrm{GHz}$ are generated. The aforementioned SIW cavity modes get perturbed by printing the rectangle slot (non-resonant slot) at the ground plane. As a result, the TE110 mode shifts downward from $6.85 \mathrm{GHz}$ to 6.1 $\mathrm{GHz}$.

And, a new couple modes (odd TE210 and even TE210) are generated at $9.55 \mathrm{GHz}$ and $10.85 \mathrm{GHz}$ due to perturbations in TE210 mode. These modes are merged together by placing the slot at optimum location, which widen the bandwidth. The surface current distribution of the proposed design at different resonances is depicted in Fig. 5. It is evident that the quality factor (Q) of the hybrid mode at $9.75 \mathrm{GHz}$ is less than that of the hybrid mode at $10.65 \mathrm{GHz}$, which can be noticed by comparing Fig. 3a and b. At both the resonances, surface current is mostly concentrated above the non-resonant slot with a minimal amount of field in the lower half. To know the variations in the fractional bandwidth, the slot width is changed as shown in Fig. 4. As a result, the impedance matching properties has been greatly affected. At optimum Ws $=1.4 \mathrm{~mm}$, the fractional bandwidth was obtained maximum. Mathematically, fractional (percentage) bandwidth is calculated from the equation (2). 
$\%$ Fractional Bandwidth $=2 \times \frac{f_{H}-f_{L}}{f_{H}+f_{L}} \times 100 \%$

Where fL - lower frequency (S11 <-10 dB) ; fL - upper frequency $(\mathrm{S} 11<-10 \mathrm{~dB})$.

Figure 2: Real impedance (Z11) plot

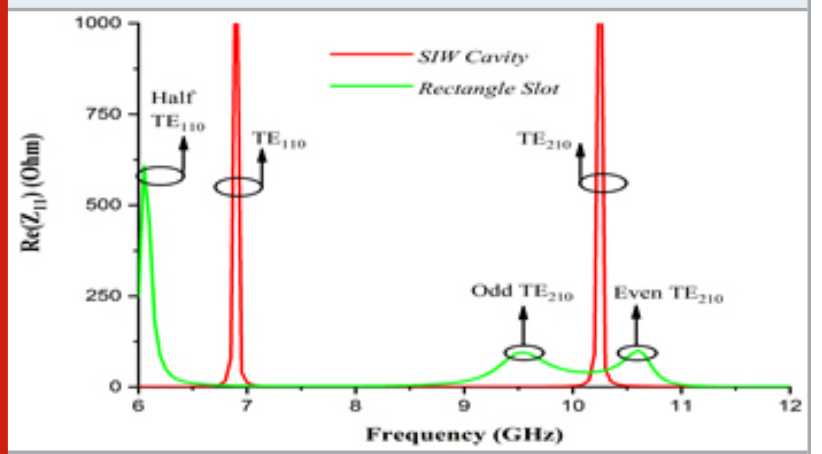

Figure 3: Surface current distribution at a $9.75 \mathrm{GHz}$ and b $10.65 \mathrm{GHz}$

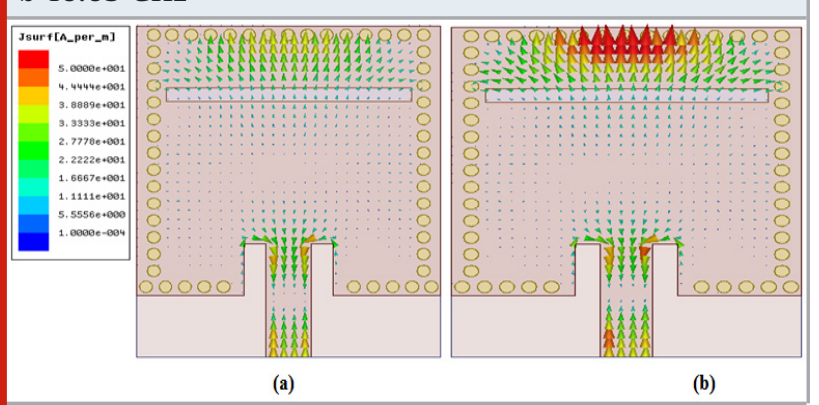

Figure 4: Changes in fractional bandwidth by varying slot width $\mathrm{w}_{\mathrm{s}}$

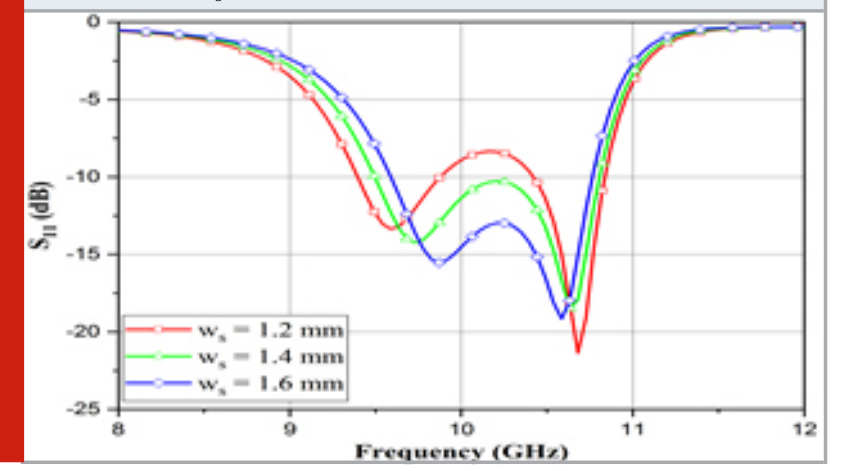

\section{RESULTS AND DISCUSSION}

The proposed design is completely designed with single substrate. The simulated result of the reflection coefficient (S11) confirms the wideband response as depicted in Fig. 5. It can be substantiated from the figure that, the simulated frequencies resonances are $9.75 \mathrm{GHz}$ and $10.65 \mathrm{GHz}$. The simulated impedance bandwidths (for below $-10 \mathrm{~dB}$ ) are $1.3 \mathrm{GHz}(12.8 \%$ ) covering from $9.5 \mathrm{GHz}$ to $10.8 \mathrm{GHz}$. The simulated gain performance of the antenna is included in Fig. 7. The gain remains consistent, with a peak gain of $6.44 \mathrm{dBi}$ and $7.1 \mathrm{dBi}$ is achieved at $9.75 \mathrm{GHz}$ and $10.65 \mathrm{GHz}$, respectively. From the gain expression (3), the gain is proportional to aperture (slot) area. It is also verified from the simulation as shown in Fig. 6.

$$
\mathrm{G}=\frac{4 \pi}{\lambda^{2}} \varepsilon_{a p} A_{p}
$$

Figure 5: Simulated reflection coefficient (S11) and gain of the proposed antenna

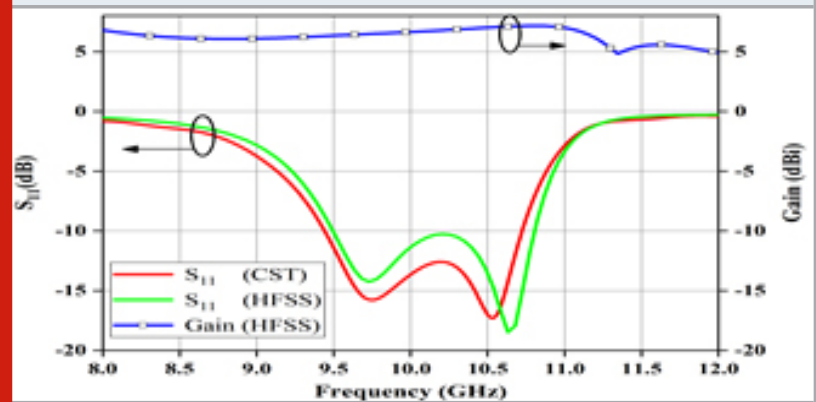

Figure 6: Analysis of gain of the proposed antenna for different values of slot width Ws

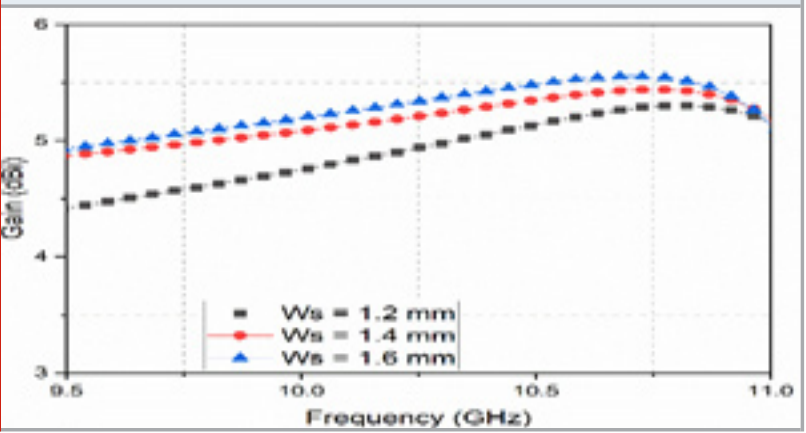

Figure 6: Radiation patterns of the wideband antenna at a $9.75 \mathrm{GHz}$ b $10.65 \mathrm{GHz}$

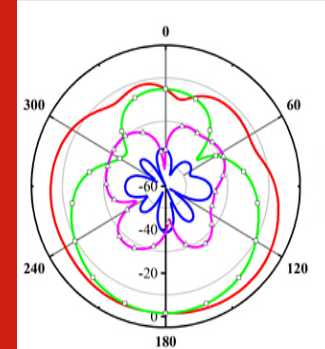

(a)

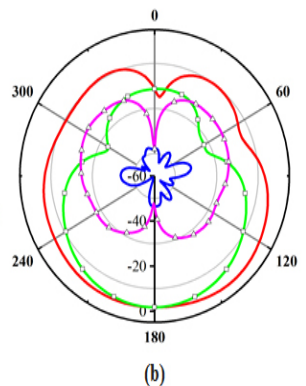

(b)
The simulated far-field pattern of the antenna in two cut-planes, which are corresponding to XZ-plane $(\varphi=00)$ and YZ-plane $(\varphi=900)$ at two frequencies are shown in Fig. 8. It is found from the simulated results that, the peak cross-polarization level in the XZ-plane and YZ-plane is $-31 \mathrm{~dB}$ and $-21 \mathrm{~dB}$, respectively at a lower resonant frequency in the broadside direction. At $10.65 \mathrm{GHz}$, the peak cross-pol level is $-35 \mathrm{~dB}$ and -20 $\mathrm{dB}$ in the XZ-plane and YZ-plane, respectively. The 
simulated front-to-back ratio (FTBR) of the proposed design is about $14 \mathrm{~dB}$ and $18 \mathrm{~dB}$ respectively at $9.75 \mathrm{GHz}$ and $10.65 \mathrm{GHz}$. To indicate the essence of the proposed study, a comparison of different parameters of the proposed design and the previously published designs are listed in Table 2. It may be observed that the proposed antenna showcase the flexibility in tuning impedance bandwidth and renders a better bandwidth performance at two frequencies as compared to works presented in Table 2 by using single cavity mode.

Table 2. Comparison among proposed antenna and some previously reported SIW CBSA

\begin{tabular}{|l|c|c|c|c|c|c|}
\hline Properties & Year & Freq. band & FBW (\%) & Gain (dBi) & Structure & h (mm) \\
\hline Mukherjee S and Biswas A et. al & 2012 & $\mathrm{X}$ & 6.3 & 6 & Simple & 0.5 \\
\hline Mukherjee and Biswas A S et. al & 2014 & $\mathrm{X}$ & 9.4 & 3.7 & Complex & 0.787 \\
\hline Kumar A and Raghavan S & 2017 & $\mathrm{Ku}$ & 11 & 8 & Complex & 1.57 \\
\hline Heydarzadeh F and Neshati MH & 2018 & $\mathrm{Ku}$ & 5.7 & 6.4 & Complex & 1.57 \\
\hline Chaturvedi D & 2020 & $\mathrm{C}$ & 5.2 & 7.15 & Complex & 1.524 \\
\hline Ali HA and Massoni E et. al & 2018 & $\mathrm{~S}$ & 3.72 & 4.42 & Complex & 1.52 \\
\hline This work & 2020 & $\mathrm{X}$ & 12.8 & 7.1 & Simple & 1.57 \\
\hline
\end{tabular}

\section{CONCLUSION}

A low-profile bandwidth-enhanced planar slot antenna using SIW technology is designed and analyzed in this article. The proposed design is loaded with a simple rectangle slot for radiating the electromagnetic waves. The radiating slot is engraved near to the upper wall of the SIW cavity, which perturb the TE210 mode to achieve bandwidth enlargement. Radiation performance and effects of parameter have been investigated. The simulation findings show a maximum gain of $7.1 \mathrm{dBi}$ and fractional bandwidth of $12.8 \%$. The proposed design still retains many benefits such as lighter weight, less fabrication cost, and easy integration with planar circuits.

\section{REFERENCES}

Ali HA, Massoni E, Silvestri L, Bozzi M, Perregrini $\mathrm{L}$ and Gharsallah A, "Increasing the bandwidth of cavity-backed SIW antennas by using stacked cavities," Int J Microw Wirel Tech, vol. 10, 2018, doi: 10.1017/ S1759078718000478.

Baghernia E and Neshati MH, "Development of a broadband substrate integrated waveguide cavity backed slot antenna using perturbation technique," Appl Comput Electromagn Soc J, vol. 29, 2014.

Bollavathi L, Dorai V and Alapati S, "Wideband planar substrate integrated waveguide cavity-backed amended dumbbell-shaped slot antenna," AEU-Int J Ele Comm Eng, vol. 127, 2020, doi: 10.1016/j.aeue.2020.153489. Chaturvedi D, "SIW cavity-backed 240 inclined-slots antenna for ISM band application," Int J RF Microw Comput Aided Eng, vol. 30, 2020, doi: 10.1002/ mmce.22160.

Dashti H and Neshati MH, "Development of low profile patch and semi-circular SIW cavity hybrid antennas," IEEE Trans Antennas Propag, vol. 62, 2014, doi: 10.1109/ TAP.2014.2334708.
Feng C, Yang J, Yan L, Zhang Y, Geng Y and Zhang W, "Broadband substrate-integrated waveguide slot antenna," Electromagnetics, vol. 32, 2012, doi: 10.1080/02726343.2012.686844.

Heydarzadeh F and Neshati MH, "Design and development a wideband SIW based cavity-backed slot antenna using two symmetrical circular corner perturbations," Int J RF Microw Comput Aided Eng, vol. 28, 2018, doi: 10.1002/mmce.21552.

Kumar A and Raghavan S, "Wideband slotted substrate integrated waveguide cavity-backed antenna for Ku-band application," Microw Opt Technol Lett, vol. 59, 2017, doi: 10.1002/mop.30594.

Kumar A, Saini G and Singh S, "A review on future planar transmission lines. Cognet Engineering," vol. 3, 2016.

Lokeshwar B, Venkatasekhar D and Sudhakar A, "Dualband low profile SIW cavity-backed antenna by using bilateral slots," Prog In Electromagn Res C, vol. 100, 2020, doi: 10.2528/PIERC20021201

Lokeshwar B, Venkatasekhar D and Sudhakar A, "Wideband low-profile SIW cavity-backed antenna bilateral slots antenna for X-band application,” Prog In Electromagn Res M, vol. 97, 2020, doi: 10.2528/ PIERM20083004.

Luo GQ, Hu ZF, Dong LX and Sun LL, "Planar slot antenna backed by substrate integrated waveguide cavity," IEEE Antenna Wireless Propag Lett, vol. 7, 2008, doi: 10.1109/LAWP.2008.923023.

Luo GQ, Hu ZF, Li WJ, Zhang XH, Sun LL and Zheng JF, "Bandwidth-enhanced low-profile cavity-backed slot antenna by using SIW cavity modes," IEEE Trans Antennas Propag, vol. 60, 2012, doi: 10.1109/ TAP.2012.2186226.

Mukherjee S, Biswas A and Srivastava KV, "Bandwidth 
enhancement of substrate integrated waveguide cavity backed slot antenna by offset feeding technique," IEEE Appl Electromagn Conf, 2013.

Mukherjee S, Biswas A and Srivastava KV, "Broadband substrate integrated waveguide cavity-backed bow-tie slot antenna," IEEE Antenna Wireless Propag Lett, vol. 13, 2014, doi: 10.1109/LAWP.2014.2330743.
Niu BJ and Tan JH, "Bandwidth enhancement of lowprofile SIW cavity antenna with bilateral slots," Progress In Electromagn Res Lett, vol. 82, 2019, doi: 10.2528/ PIERL18102505.

Varnoosfadetrani MV, Lu J and Zhu B, "Matching slot role in bandwidth enhancement of SIW cavity-backed slot antenna," Asia-Pacific Conf on Antennas and Propag, 2014. 